\title{
NADPH Oxidase RbohD and Ethylene Signaling are Involved in Modulating Seedling Growth and Survival Under Submergence Stress
}

\author{
Chen-Pu Hong ${ }^{1}$, Mao-Chang Wang ${ }^{2}$ and Chin-Ying Yang ${ }^{1, * \mathbb{C}}$ \\ 1 Department of Agronomy, National Chung Hsing University, Taichung 40227, Taiwan; xo7961@hotmail.com \\ 2 Department of Accounting, Chinese Culture University, Taipei 11114, Taiwan; wmaochang@yahoo.com.tw \\ * Correspondence: emiyang@dragon.nchu.edu.tw; Tel.: +886-4-22840777 (ext. 608); Fax: +886-4-22877054
}

Received: 2 March 2020; Accepted: 7 April 2020; Published: 8 April 2020

\begin{abstract}
In higher plants under low oxygen or hypoxic conditions, the phytohormone ethylene and hydrogen peroxide $\left(\mathrm{H}_{2} \mathrm{O}_{2}\right)$ are involved in complex regulatory mechanisms in hypoxia signaling pathways. The respiratory burst oxidase homolog $\mathrm{D}(\mathrm{RbohD})$, an NADPH oxidase, is involved in the primary stages of hypoxia signaling, modulating the expression of downstream hypoxia-inducible genes under hypoxic stress. In this study, our data revealed that under normoxic conditions, seed germination was delayed in the rbohD/ein2-5 double mutant, whereas postgermination stage root growth was promoted. Under submergence, the rbohD/ein2-5 double mutant line had an inhibited root growth phenotype. Furthermore, chlorophyll content and leaf survival were reduced in the rbohD/ein2-5 double mutant compared with wild-type plants under submerged conditions. In quantitative RT-PCR analysis, the induction of Ethylene-responsive factor 73/hypoxia responsive 1 (AtERF73/HRE1) and alcohol dehydrogenase 1 (AtADH1) transcripts was lower in the rbohD/ein2-5 double mutant during hypoxic stress than in wild-type plants and in $r b o h D$ and ein $2-5$ mutant lines. Taken together, our results indicate that an interplay of ethylene and RbohD is involved in regulating seed germination and post-germination stages under normoxic conditions. Moreover, ethylene and RbohD are involved in modulating seedling root growth, leaf chlorophyll content, and hypoxia-inducible gene expression under hypoxic conditions.
\end{abstract}

Keywords: ethylene; Ein2; germination; RbohD; submergence; hypoxia

\section{Introduction}

Climate change-induced flooding is a major global natural disaster. Flooding and heavy rain can cause soil compaction, reducing soil oxygen concentration and resulting in hypoxic stress-induced plant damage. The plant hormone ethylene participates in regulating stress-inducible genes to help plants to adapt to various environmental stresses, especially in hypoxia signaling caused by flooding [1-3].

Ethylene controls diverse physiological pathways involved in plant growth and developmental processes including the regulation of seed germination and leaf senescence and the promotion of pollen tube growth and fruit ripening [4-6]. Ethylene also contributes to plant responses to different biotic and abiotic stresses such as insect or microbial infections, drought, and salt conditions [7-9]. Several studies have shown that the ER-located membrane protein ETHYLENE INSENSITIVE 2 (EIN2) acts as a key signal transducer that positively signals downstream to members of the ETHYLENE INSENSITIVE 3 (EIN3) family of transcription factors located in the nucleus. EIN3 further binds to the promoters of ethylene-response genes, activating their expression in an ethylene-dependent manner to activate downstream ethylene responses $[10,11]$. 
Under oxygen deficient conditions, ethylene plays a major role in the regulation of abscisic acid (ABA) and gibberellic acid (GA) to influence cell elongation [12]. In addition to cell elongation, ethylene-induced programmed cell death through reactive oxygen species (ROS) production leads to the formation of aerenchyma and emergence of adventitious roots in maize and rice [13-15]. Hydrogen peroxide $\left(\mathrm{H}_{2} \mathrm{O}_{2}\right)$ acts as a secondary messenger downstream of the ethylene signal to promote aerenchyma formation under oxygen-deficient conditions [16]. $\mathrm{H}_{2} \mathrm{O}_{2}$ is a type of ROS. ROS include $\mathrm{H}_{2} \mathrm{O}_{2}$, superoxide anion radicals $\left(\mathrm{O}_{2}{ }^{-}\right)$, hydroxyl radicals $(\mathrm{OH})$, and singlet oxygen $\left({ }^{1} \mathrm{O}_{2}\right)$, all of which are byproducts of aerobic metabolism [17]. NADPH oxidases, also named respiratory burst oxidase homologs (RBOHs), catalyze superoxide radical generation in plant apoplasts. Subsequently, superoxide radicals are converted into $\mathrm{H}_{2} \mathrm{O}_{2}$ by the activity of cell wall-localized antioxidant enzymes termed superoxide dismutases (SODs). $\mathrm{H}_{2} \mathrm{O}_{2}$ regulates the induction of ethylene-responsive factor 73 (ERF73) and alcohol dehydrogenase 1 (ADH1) expression under oxygen deprivation [18,19]. In Arabidopsis thaliana, $\mathrm{RBOHs}$ are members of a multigene family composed of $10 \mathrm{RBOH}$ genes (AtRBOH A-J) that participate in ROS production in response to environmental stresses [20].

Plant RBOHs display different expression patterns during developmental processes and in response to various abiotic stresses and biotic interactions, either pathogenic or symbiotic [21]. AtRBOHC was revealed to be activated in $\mathrm{Ca}_{2}{ }^{+}$-dependent signaling triggered by the mechanical stimulation of root hairs [22]. Mild salt stress reportedly increases AtRbohD transcript levels, and AtRbohD and AtRbohF are involved in the ABA signaling network in guard cells $[23,24]$. AtRbohD mediates rapid systemic signaling in response to wounding, heat, cold, high-intensity light, and salinity stresses [25].

Our previous studies revealed that the accumulation of $\mathrm{H}_{2} \mathrm{O}_{2}$ was reduced in ein2-5 and rbohD-knockout (rbohD-ko) mutants during hypoxic stress. The induction of hypoxia-inducible genes was also reduced in rbohD-ko mutants under hypoxic stress. AtRbohD plays a major role in the early stages of the stress response to oxygen deprivation $[19,26]$. Although AtRbohD is involved in hypoxia signaling, little is known about the relationship between ethylene and $\mathrm{RbohD}$ in submergence stress. In this study, to clarify the functional relationship between ethylene and $\mathrm{H}_{2} \mathrm{O}_{2}$ in the hypoxia signaling pathway, we analyzed rbohD/ein 2-5 double mutant and wild-type plants under hypoxic stress. Our results demonstrate that the interplay between ethylene and $\mathrm{H}_{2} \mathrm{O}_{2}$ is involved in modulating seed germination, seedling root growth, leaf chlorophyll content, and hypoxia-inducible gene expression under hypoxic conditions.

\section{Results}

2.1. The rbohd/ein2-5 Double Mutant Exhibited Ethylene Insensitive, Delayed Seed Germination and Increased Postgermination Root Growth

The induction of $\mathrm{H}_{2} \mathrm{O}_{2}$ and levels of $A t E R F 73 / H R E 1$ and $A D H 1$ are reduced in $r b o h D$ and ein2-5 single mutants under hypoxic stress $[19,26]$. To further investigate the interplay of ethylene and $\mathrm{H}_{2} \mathrm{O}_{2}$ signaling during hypoxia, we obtained rbohD/ein2-5 double mutant lines by crossing single $r b o h D$ and ein 2-5 homozygous mutants. After seeds were grown on 1/2 strength Murashige and Skoog (MS) medium with or without 1-aminocyclopropane-1-carboxylic acid (ACC) treatment for $4 \mathrm{~d}$ in dark conditions, the etiolated seedlings of the rbohD/ein2-5 double mutant line did not exhibit the triple response (Figure 1a). Increased $R b o h D$ transcript levels were not induced in the $r b o h D / e i n 2-5$ double mutant line after hypoxic treatment (Figure 1b).

The rbohD/ein2-5 double mutant seeds germinated more slowly than wild-type, $r b o h D$, and ein2-5 single mutants under normaxic conditions; $90 \%, 85 \%$, and $91 \%$ of wild-type, rbohD, and ein2-5 single mutant seeds germinated after $2 \mathrm{~d}$, whereas only $56 \%$ of rbohD/ein $2-5$ double mutant seeds germinated. Germination was largely completed after $3 \mathrm{~d}$ incubation (Figure 2a,b). The mean germination time of seeds from wild-type, rbohD and ein 2-5 single mutants, and that from the rbohD/ein2-5 double mutant, was $1.98,2.10,2.03$, and $2.35 \mathrm{~d}$, respectively (Figure 2c). 
(a)

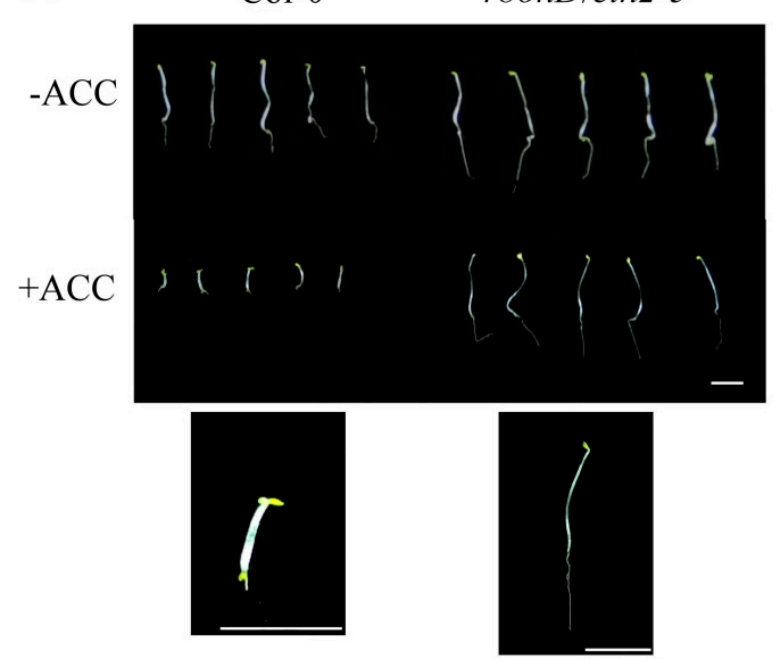

(b)

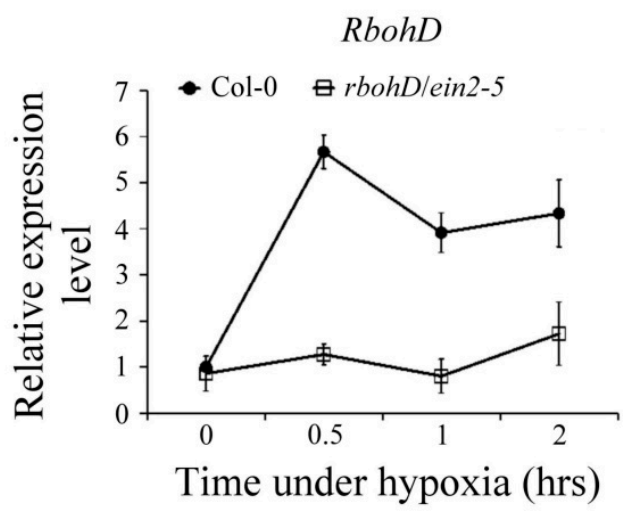

Figure 1. Phenotypes of wild-type Col-0 and rbohD/ein2-5 double mutants in Arabidopsis. (a) The wild-type (Col-0) and double mutant (rbohD/ein2-5) seeds were grown on 1/2 MS medium with $5 \mu \mathrm{M}$ ACC or without ACC for $4 \mathrm{~d}$ under dark conditions. Bar $=0.5 \mathrm{~cm}$. (b) Quantitative RT-PCR analyses of transcript levels of RbohD in Arabidopsis Col-0 and rbohD/ein2-5 double mutants in response to hypoxic stress for $0,0.5,1$, and $2 \mathrm{~h}$. Total RNAs were isolated from roots of 14 -day-old seedlings after hypoxia treatment at indicated times and levels of $R b o h D$ mRNA were determined. Relative transcript amounts were calculated and normalized to Actin mRNA levels. Values represent means \pm SD from five biologically independent experiments.

(a)

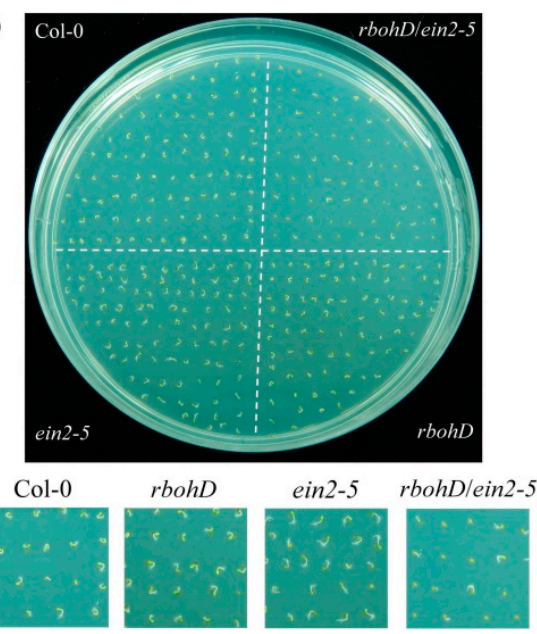

(b)
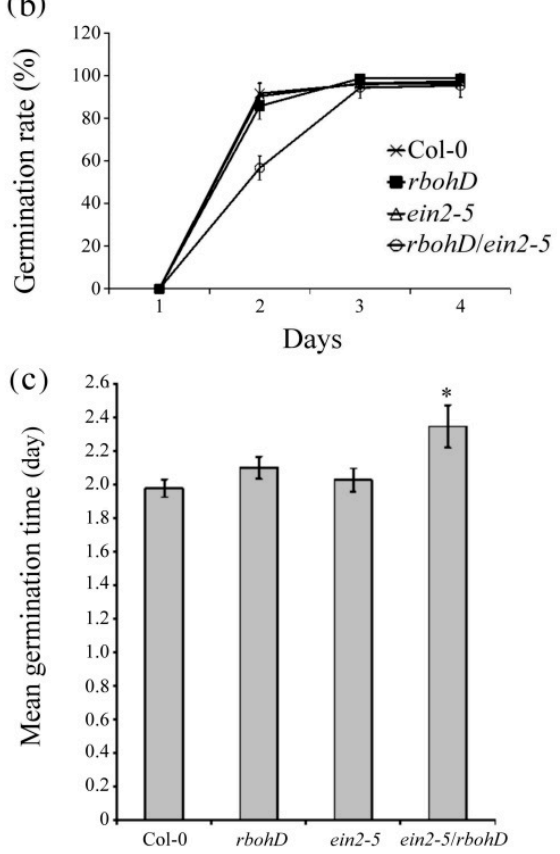

Figure 2. Germination assay of wild-type, rbohD, ein2-5 and rbohD/ein2-5 mutants. (a) Germination of wild-type, $r b o h D$ and ein2-5 single mutants, and double mutant $r b o h D / e i n 2-5$ seeds. Seeds were sown in $1 / 2 \mathrm{MS}$ medium and grown for $3 \mathrm{~d}$ at $4{ }^{\circ} \mathrm{C}$ in dark conditions; photographs were taken after $2 \mathrm{~d}$. $(\mathbf{b}, \mathbf{c})$ Germination rates and mean germination times of wild-type, rbohD and ein2-5 single mutants, and double mutant $r b o h D / e i n 2-5$ seeds. Seeds were scored for 1, 2, 3, and $4 \mathrm{~d}$ after sowing from at least 100 seeds of each genotype with three replicates each. Error bars represent SD. ${ }^{*} p<0.05$, versus wild-type (Student's $t$ test). 
To determine whether ethylene and $\mathrm{H}_{2} \mathrm{O}_{2}$ signaling affected postgermination seedling development, the rbohD/ein2-5 double mutant seedlings were grown for $4,6,8,10$, and $12 \mathrm{~d}$. The root lengths of the rbohD/ein2-5 double mutant lines were significantly longer than those of the wild-type seedlings (Figure 3a). When grown for 4, 6, 8, 10, and $12 \mathrm{~d}$, wild-type seedlings developed roots with average lengths of $0.42,1.00,1.57,2.09$, and $2.32 \mathrm{~cm}$, respectively, whereas the average root length of rbohD/ein2-5 double mutants was $0.36,1.45,2.52,2.95$, and $3.09 \mathrm{~cm}$, respectively (Figure $3 b$ ). These results indicate that in the rbohD/ein2-5 double mutant, seed germination was delayed and the postgermination root growth rate increased.
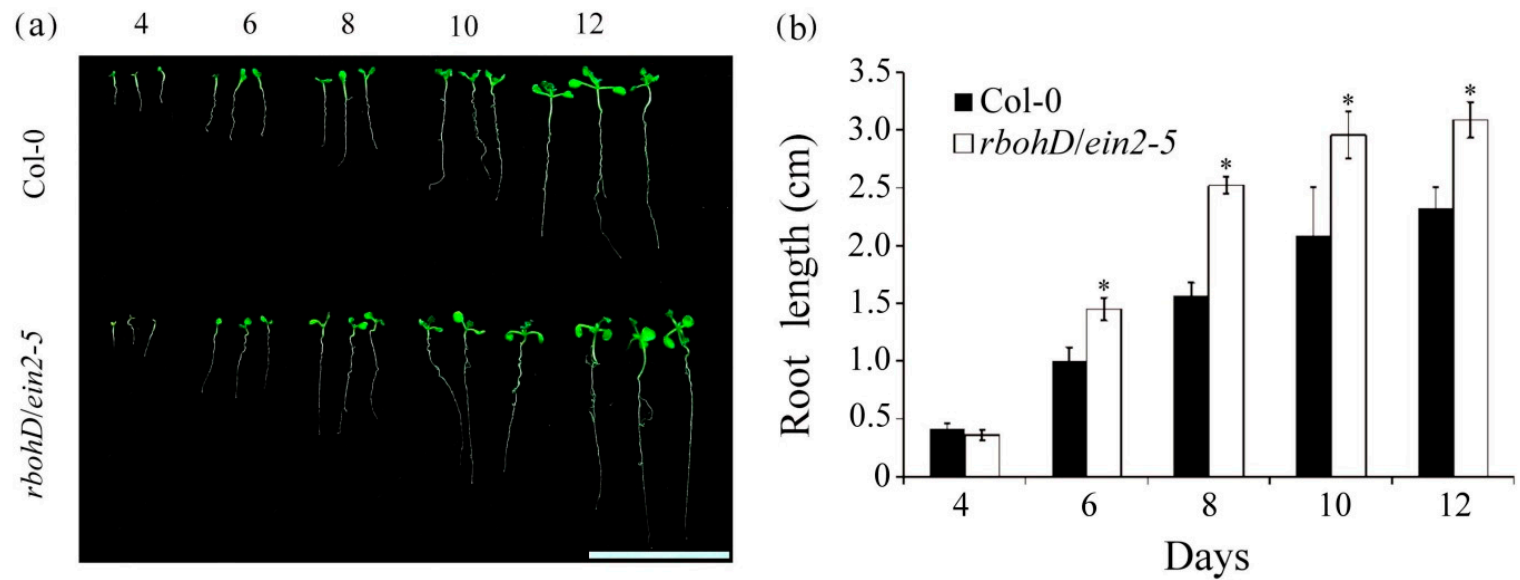

Figure 3. Comparison of root growth in wild-type and rbohD/ein2-5 double mutant seedlings. (a) Phenotypes of seedlings grown on 1/2 MS medium for 4,6,8,10, and $12 \mathrm{~d}$. Bar $=2 \mathrm{~cm}$. (b) Average root length of seedlings grown on $1 / 2 \mathrm{MS}$. Error bars represent SD of 100 seedlings of each genotype, obtained from three biologically independent experiments. ${ }^{*} p<0.05$, versus wild-type (Student's $t$ test).

\subsection{The rbohD/ein2-5 Double Mutant Line Exhibited no Inhibition of Root Growth Following Submergence}

Ethylene plays a role in inhibiting root length during plant developmental processes. Hydrogen peroxide also functions in inhibiting root length $[27,28]$. To determine whether ethylene signaling and $\mathrm{H}_{2} \mathrm{O}_{2}$ affect root growth in response to submergence, 7-day-old wild-type and rbohD/ein2-5 double mutant seedlings were treated with normoxic or submerged conditions for $7 \mathrm{~d}$. Root lengths were significantly reduced in wild-type plants compared with the rbohD/ein2-5 double mutant lines (Figure 4a). The average root lengths of wild-type and the rbohD/ein2-5 double mutant under the normaxic condition were 1.94 and $2.83 \mathrm{~cm}$, respectively, whereas the average root lengths of wild-type and the rbohD/ein2-5 double mutant under submergence were 1.34 and $3.19 \mathrm{~cm}$, respectively (Figure $4 \mathrm{~b}$ ). The root lengths of the rbohD/ein2-5 double mutant increased by $113 \%$ under submerged conditions compared with under the normaxic condition, whereas those of wild-type plants decreased by $69 \%$. These results indicate that root growth was not inhibited in submerged rbohD/ein2-5 double mutant lines.

\subsection{Reduced Chlorophyll Content and Survival of rbohD/ein2-5 Double Mutant Plants under Submerged Conditions}

To further assess the role of ethylene and $\mathrm{H}_{2} \mathrm{O}_{2}$ signaling under submerged conditions, chlorophyll content was determined during submergence. The 7-day-old wild-type and rbohD/ein2-5 double mutant seedlings were submerged for $12 \mathrm{~d}$. The rbohD/ein 2-5 double mutant exhibited more severe leaf etiolation than the wild-type plants did under submergence (Figure 5a). Contents of chlorophyll a and total chlorophyll were significantly decreased in the rbohD/ein2-5 double mutant line after submergence treatment (Figure $5 b$ ). This effect was also observed in 7-day-old seedlings submerged for $12 \mathrm{~d}$ then left to recover for $5 \mathrm{~d}$. The degree of leaf damage following submergence of the etiolated seedlings was analyzed and classified according to an index scale ranging from 1 to 4 , where index scores of 1 and 2 represent $100 \%$ and over $50 \%$ green leaf area, respectively, and scores 3 and 4 represent less than $50 \%$ 
and $0 \%$ green leaf area, respectively. These data indicate that more than $95 \%$ of the rbohD/ein $2-5$ double mutant seedlings exhibited a phenotype with leaf damage (Figure 6a,b), suggesting that ethylene and $\mathrm{H}_{2} \mathrm{O}_{2}$ signaling positively regulate aboveground leaf survival under submergence stress.
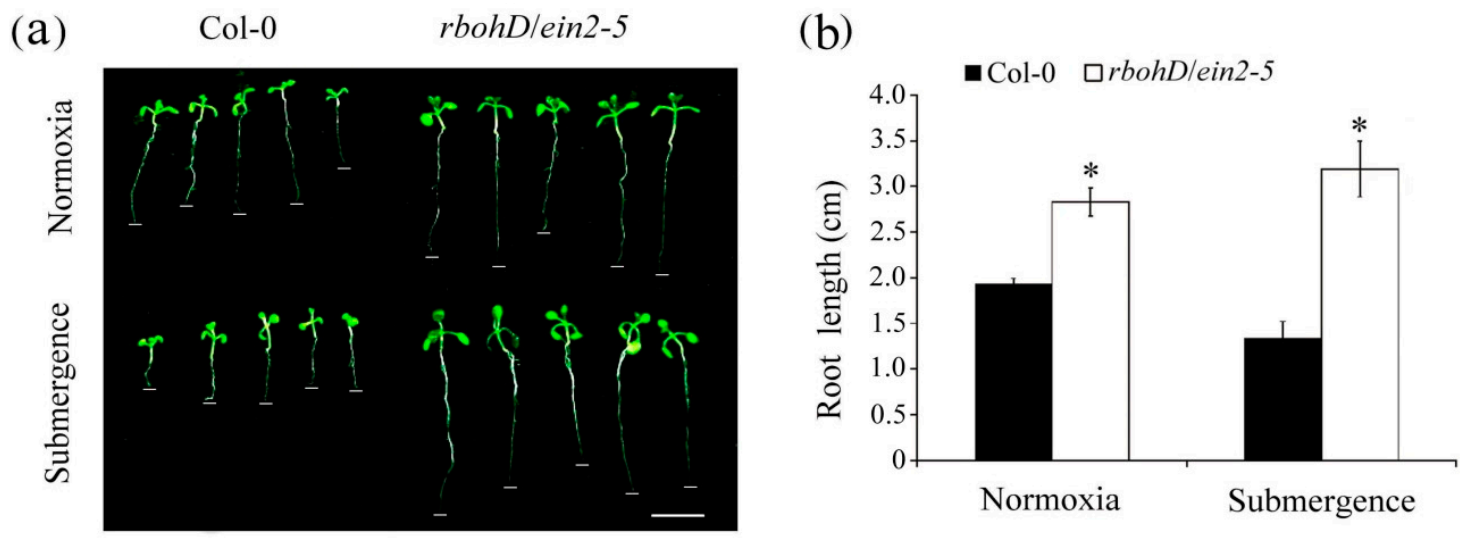

Figure 4. Comparison of root growth in wild-type and rbohD/ein2-5 double mutant seedlings after submergence. (a) Phenotypes of seedlings grown on 1/2 MS medium for $14 \mathrm{~d}$ and then treated with submerged conditions for an additional $7 \mathrm{~d}$. Bar $=1 \mathrm{~cm}$. (b) Average root length of seedlings grown under normaxic condition and submerged conditions. Error bars represent SD for at least 100 seedlings of each genotype, obtained from three biologically independent experiments. ${ }^{*} p<0.05$, versus wild-type plants (Student's $t$ test).

(a)

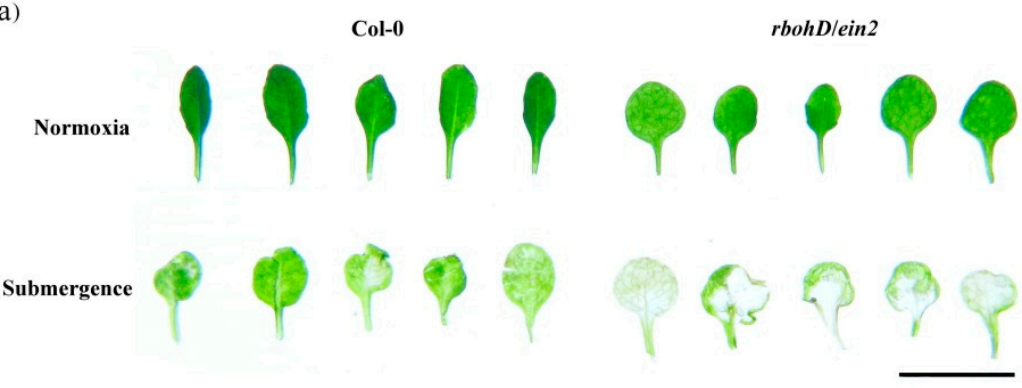

(b)
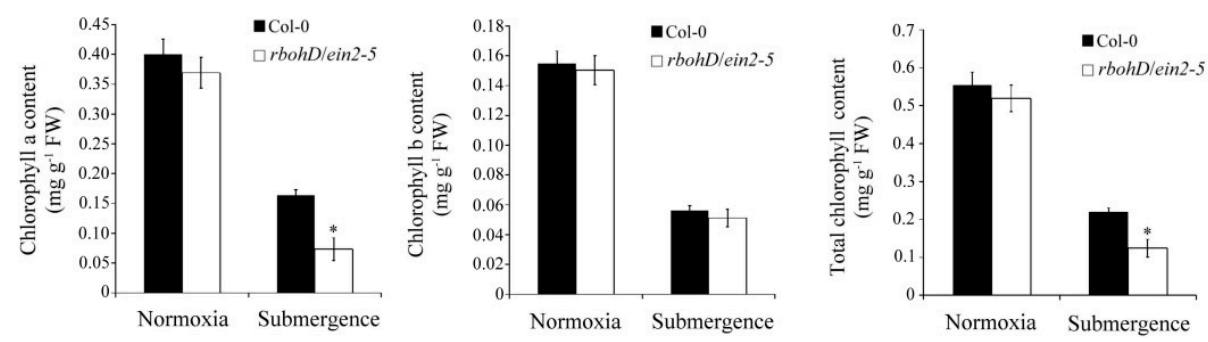

Figure 5. Chlorophyll content of wild-type plants and rbohD/ein2-5 double mutants after submergence stress. (a) Phenotype of 7-day-old wild-type plants (Col-0) and double mutant rbohD/ein2-5 leaves after treatment under normoxic conditions and submerged conditions for $12 \mathrm{~d}$. Bar $=1 \mathrm{~cm}$. (b) Contents of chlorophyll a, b, and total chlorophyll of 7-day-old seedlings after treatment under normoxic conditions and submerged conditions for $12 \mathrm{~d}$. Values represent means \pm SD from three biologically independent experiments. ${ }^{*} p<0.05$, versus wild-type (Student's $t$ test). 
(a)

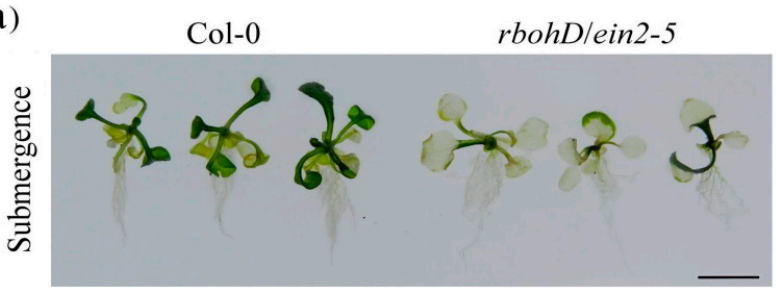

(b)

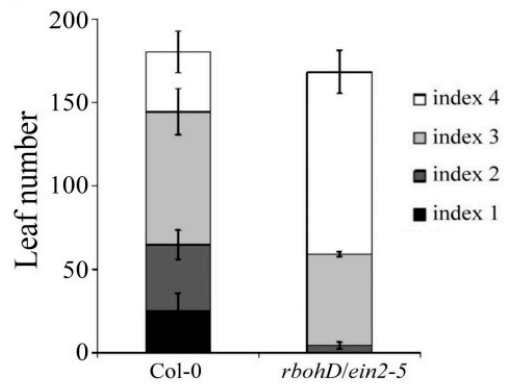

Figure 6. Sensitivity of the rbohD/ein2-5 double mutant to submerged conditions. (a) Phenotypes of 7-day-old wild-type plants and rbohD/ein2-5 double mutant seedlings after $12 \mathrm{~d}$ of submergence and $5 \mathrm{~d}$ of subsequent recovery. Bar $=1 \mathrm{~cm}$. The photograph provides the results for three independent seedlings. (b) Quantification of the phenotype. Levels of damage were defined using an index based on the percentage of chlorotic leaves. Index $1=100 \%$ green leaves, Index $2=$ over $50 \%$ green leaves, Index $3=$ less than $50 \%$ green leaves, and Index $4=0 \%$ green leaves. The same results were obtained from three independent experiments $(n \geq 25)$.

\subsection{Effects of the rbohD/ein2-5 Double Mutant Line on Hypoxia-Inducible Genes under Hypoxic Stress}

To determine how ethylene and $\mathrm{H}_{2} \mathrm{O}_{2}$ signaling affects hypoxia responses, we examined the expression of AtERF73/HRE1 and $A D H 1$ in wild-type, rbohD and ein2-5 single mutants, and the rbohD/ein2-5 double mutant using qRT-PCR. The results indicate that under hypoxic conditions, the induction of AtERF73/HRE1 and ADH1 mRNA was significantly reduced in rbohD and ein2-5 single mutants and in the rbohD/ein2-5 double mutant lines compared with wild-type plants (Figure 7a,b). The rbohD/ein2-5 double mutant had the most pronounced reduction in hypoxia-induced transcription. Taken together, these results suggest that ethylene and $\mathrm{H}_{2} \mathrm{O}_{2}$ signaling synergistically regulated hypoxia-inducible gene responses.
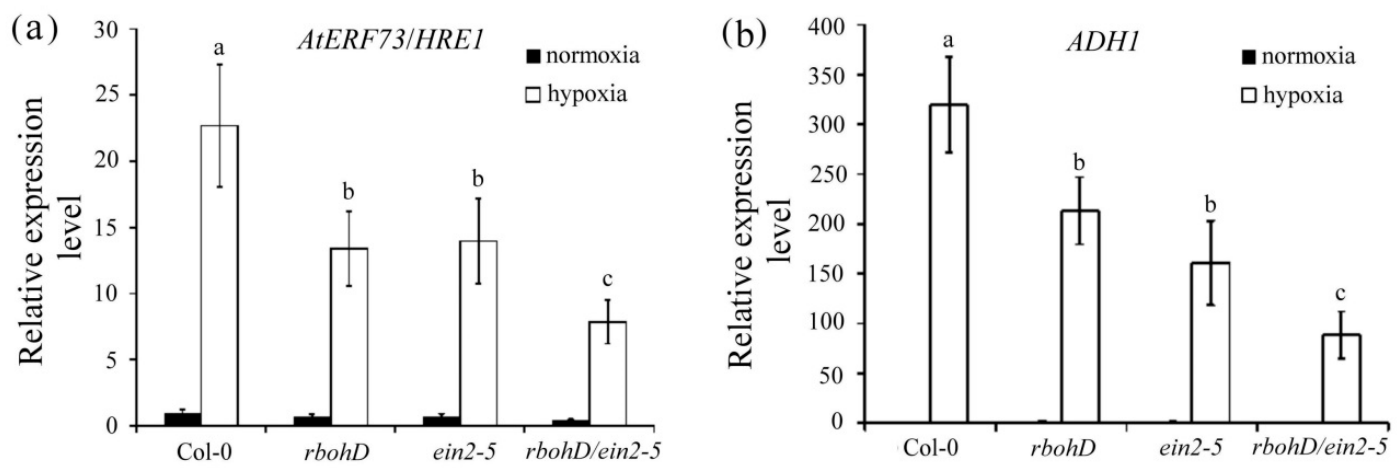

Figure 7. Transcript levels of hypoxia-inducible genes encoding AtERF73/HRE1 and ADH1 in rbohD/ein2-5 lines after hypoxia treatment. Total RNAs were isolated from roots of 14-day-old Col-0, rbohD, ein2-5, and rbohD/ein2-5 seedlings after $3 \mathrm{~h}$ of hypoxia treatment. Quantitative RT-PCR analyses of transcript levels of AtERF73/HRE1 (a) and ADH1 (b) genes. Values are means \pm SD from three biologically independent experiments $(n=3)$. Values with different letters are significantly different at $p<0.05$, according to a post-hoc LSD test. 


\section{Discussion}

Plants are sessile organisms that have evolved integrated complex regulation systems to respond to stress. Oxygen deprivation is a common abiotic stress often associated with flooding. It affects plant growth, development, and survival. The role of ethylene in oxygen sensing and signaling is complex [29]. Recent studies have demonstrated that when submergence is established, gas diffusion of ethylene is restricted, and it is trapped in the plant, triggering its signaling pathway at early submergence. When submergence is prolonged, ethylene synthesis is reduced due to hypoxia; group VII ethylene response factor (ERFVII) activity is activated by hypoxia signaling [30-32]. In our previous reports, we demonstrated that the NADPH oxidase RbohD plays a major role in the early stages of hypoxic stress responses. Ethylene signaling modulates $\mathrm{H}_{2} \mathrm{O}_{2}$ signaling by regulating the expression of Rboh genes [19,26]. RbohD triggers cell death following fungal infection, and crosstalk between the salicylic acid and ethylene signaling pathways inhibits death in neighboring cells [33]. Furthermore, the double null mutant atrbohD/F is more sensitive to oxygen deficiency than wild-type plants and single mutants atrbohD and atrbohF are [34]. Little is known about the ethylene-mediated regulation of RbohD in the hypoxia signaling pathway.

The present study revealed that rbohD/ein2-5 double mutants had delayed seed germination but increased root growth compared with wild-type plants (Figures 2 and 3). During seed germination, endogenous ethylene promotes seed germination by decreasing sensitivity to endogenous ABA [35]. $\mathrm{H}_{2} \mathrm{O}_{2}$, acting as a signaling molecule, mediates seed dormancy breaking and germination through the upregulation of ABA catabolism and GA biosynthesis [36]. Our data demonstrate that the mean seed germination time was significantly reduced in wild-type plants and the $r b o h D$ and ein2-5 single mutants compared with the rbohD/ein2-5 double mutant (Figure 2c), indicating that the interplay between ethylene signaling and $\mathrm{H}_{2} \mathrm{O}_{2}$ signaling modulates seed germination. Previously, we determined that under normoxic conditions, postgermination seedling root lengths of wild-type plants and rbohD single mutants do not differ [26]. Notably, the current study revealed that the rbohD/ein2-5 double mutant had faster root growth 6-12 d after germination under both normoxic (Figure 3b) and submerged (Figure 4) conditions. Ethylene has been demonstrated to inhibit root cell elongation by upregulating auxin biosynthesis in Arabidopsis seedlings; accumulated $\mathrm{H}_{2} \mathrm{O}_{2}$ also inhibits root cell elongation and root growth [37-39]. Under submerged conditions, root length is reduced by oxygen deficiency [40]. However, the rbohD/ein2-5 double mutant did not display inhibited root growth under submergence; instead, it had longer roots than wild-type plants did. These results suggest that crosstalk between ethylene signaling and $\mathrm{H}_{2} \mathrm{O}_{2}$ signaling, in addition to delaying seed germination, affects the root growth rate of postgermination seedlings under both normoxic and hypoxic conditions.

Chlorophyll absorbs the wavelengths associated with violet-blue and orange-red light within the visible light spectrum that are used in photosynthesis during plant growth and development. When plants are exposed to abiotic and biotic stresses such as drought, extreme temperature, cold, or heavy metals, chlorophyll concentration is decreased and protein degradation is increased [41-43]. Many studies have reported that ethylene is involved in the regulation of chlorophyll degradation during development or under stress conditions. When plants are submerged, chloroplasts disintegrate and photosynthetic capacity is lost [44-46]. In the present study, chlorophyll a and total chlorophyll concentration decreased significantly in rbohD/ein2-5 double mutants after submergence treatment (Figure 5). Furthermore, the seedlings of the rbohD/ein2-5 double mutant line had more leaf damage compared with wild-type plants after submergence stress (Figure 6). Some APETALA2/ethylene response factors function in an ethylene-controlled signal transduction pathway to regulate tolerance to hypoxia stress $[47,48]$. The secondary messenger, $\mathrm{H}_{2} \mathrm{O}_{2}$ production, has also been implicated in regulating tolerance to oxygen deprivation $[18,49]$. Our results indicate that under hypoxic stress, the induction of transcript levels of the hypoxia-inducible genes encoding ethylene-responsive factor 73 (ERF73) and alcohol dehydrogenase 1 (ADH1) was increased less in the rbohD/ein2-5 double mutant line than in the rbohD and ein2-5 single mutants (Figure 7). Notably, increased transcript levels of AtERF73/HRE1 and ADH1 were induced in all the lines under hypoxic conditions. This suggests 
that there are signaling elements other than ethylene and RbohD that also modulate the expression of hypoxia-responsive genes, such as AtERF73/HRE1 and ADH1. Our previous results reveal that the accumulation of $\mathrm{H}_{2} \mathrm{O}_{2}$ was reduced in rbohD-ko and ein2-5 during hypoxic stress [19,26]. In this study, both RbohD and EIN2 had a synergistic effect on seed germination and root growth at the postgermination stage under normoxic conditions and influenced submergence tolerance under oxygen deprivation conditions. Taken together, the results reported here indicate the presence of a synergistic interaction between ethylene and $\mathrm{H}_{2} \mathrm{O}_{2}$ signaling in plant development under normoxic conditions and in response to oxygen deprivation (Figure 8).

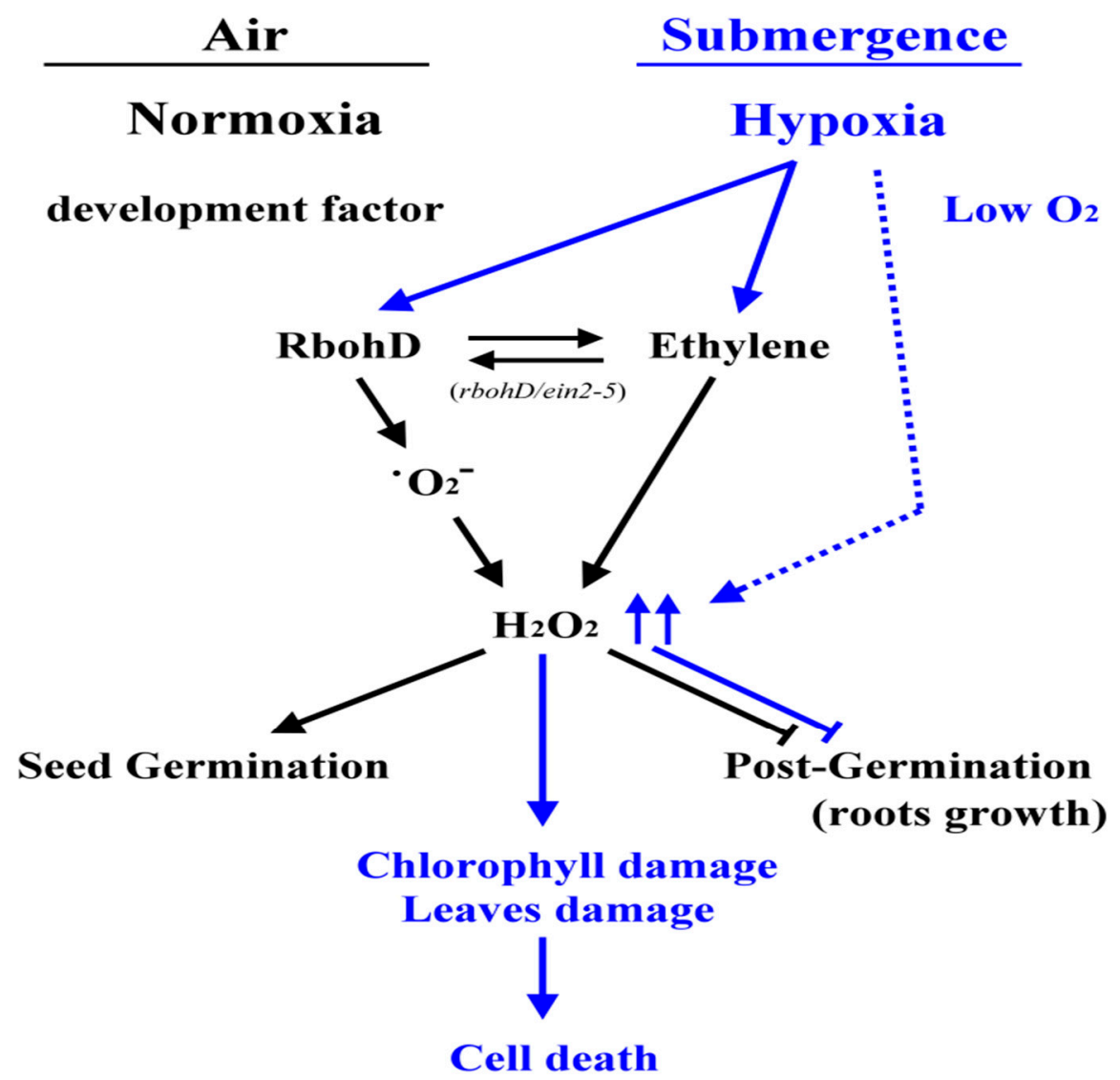

Figure 8. Schematic of the effects of RbohD-derived $\mathrm{H}_{2} \mathrm{O}_{2}$ and ethylene signaling under normoxic and hypoxic conditions. Both RbohD and EIN2 had a synergistic effect on seed germination and root growth at the postgermination stage under normoxic conditions (black line). Hypoxia triggers complex signaling pathways to increase the production of $\mathrm{H}_{2} \mathrm{O}_{2}$, leading to chlorophyll and leaves damages influencing submergence tolerance in Arabidopsis (blue line).

\section{Materials and Methods}

\subsection{Plant Materials and Growth Conditions}

Wild-type Arabidopsis thaliana (ecotype Col-0) was used in this study. The single ein2-5 and rbohD (At5g47910) T-DNA insertion mutants (salk_005253C) were obtained from Dr. L.-C. Wang and the Arabidopsis Biological Resource Center (Ohio State University, Columbus, OH, USA), respectively, with the homozygous T-DNA insertion sites confirmed by RT-PCR before use. Double homozygous mutant lines, rbohD/ein2-5, were obtained by crossing the two single mutants and then screening the F2 and F3 generation as previously described [26]. Seeds were surface sterilized in 70\% ethanol for 2 min and then in a $1 \%$ bleach solution for $15 \mathrm{~min}$ before being washed with sterilized water three times and incubated at $4{ }^{\circ} \mathrm{C}$ in the dark for $3 \mathrm{~d}$. Seeds were sown on plates with $0.7 \%(w / v)$ agar in $1 / 2$-strength Murashige and Skoog (MS) medium containing 0.5\% sucrose at $\mathrm{pH}$ 5.7. The plates were transferred to 
a growth chamber at $22{ }^{\circ} \mathrm{C}$ with a long photoperiod regimen of $16 \mathrm{~h}$ of light $\left(236 \mu \mathrm{moLm}^{-2} \mathrm{~s}^{-1}\right) /$ and $8 \mathrm{~h}$ of darkness.

For the seed germination assay, data were collected from 100 seeds of each genotype over three independent experiments. Germination was considered to have occurred when the radicles were $1 \mathrm{~mm}$ long. Germination percentage was recorded every $24 \mathrm{~h}$ for $4 \mathrm{~d}$. The number of germinated seeds was expressed as a percentage of the total number of seeds plated for the indicated times. The mean germination time was calculated to assess the time spent to germinate or emerge [50].

\subsection{Seedling Hypoxia, Submergence, and ACC Treatments}

For the hypoxia treatment, 14-day-old seedlings were placed on damp filter paper for a $10 \mathrm{~min}$ pretreatment and then onto a floating platform with their roots immersed in 1/2 MS solution. The solution was constantly supplied with $3 \% \mathrm{O}_{2} / 97 \% \mathrm{~N}_{2}$ gas in the dark to replace the oxygen in the solution. The seedling roots were collected for analysis. Other 14-day-old seedlings were placed in the dark without immersion in 1/2 MS solution as controls. For the submergence treatment, seeds were grown on 1/2-strength MS medium in a tissue cultivation box (L:W:H, $12 \mathrm{~cm} \times 9 \mathrm{~cm} \times 7 \mathrm{~cm})$ for $7 \mathrm{~d}$ and then treated with or without $250 \mathrm{~mL}$ of sterile deionized water for $12 \mathrm{~d}$. The water was drained out for the the subsequent 5-day recovery period. The root lengths of the seedlings (under normoxic conditions or submerged conditions) were measured. Data were collected from at least 100 seedlings of each genotype in three independent experiments. Photographs were taken at the end of the treatment period. For the ACC treatment, seeds were grown on $1 / 2$-strength MS medium with or without $5 \mu \mathrm{M}$ ACC in the dark for $4 \mathrm{~d}$. The phenotypes were observed, and photographs were taken at the end of the treatment period.

\subsection{Plant Chlorophyll Content and Leaf Damage Index Measurements}

For chlorophyll content assays, the content was determined according to Wintermans and De Mots (1965) after extraction in ethanol [51]. The 7-day-old seedlings were treated under normoxic conditions or submerged conditions for $12 \mathrm{~d}$. Aboveground tissue $(50 \mathrm{mg})$ was collected and ground in $2 \mathrm{~mL}$ of sodium phosphate buffer ( $50 \mathrm{mM} \mathrm{pH} \mathrm{6.8),} 40 \mu \mathrm{L}$ of which was added to $960 \mathrm{~mL}$ of $99 \%$ ethanol and incubated for $30 \mathrm{~min}$ at room temperature in the dark with gentle shaking. After centrifugation at $4{ }^{\circ} \mathrm{C}$ for $15 \mathrm{~min}$ at $1000 \times \mathrm{g}$, the absorbance values of the supernatant were measured at 665 and $649 \mathrm{~nm}$ with a spectrophotometer (Metertec SP8001) to determine to concentrations of chlorophyll a, b, and total chlorophyll. Data were collected from three independent experiments. For leaf damage index measurement, the 7-day-old seedlings were treated under submerged conditions for $12 \mathrm{~d}$ followed by $5 \mathrm{~d}$ of recovery. The levels of damage were defined as follows: Index $1=100 \%$ green leaves, Index $2=$ over $50 \%$ green leaves, Index $3=$ less than $50 \%$ green leaves, and Index $4=0 \%$ green leaves. Data were collected from three independent experiments. Each experiment involved the use of at least 25 seedlings. Photographs were taken at the end of experiment. For the hypoxia treatment, 14-day-old seedlings were placed on a floating platform with their roots immersed in 1/2 MS solution supplemented with $0.5 \%(w / v)$ Suc at $\mathrm{pH}$ 5.7. The solution was constantly supplied with $3 \%(v / v) \mathrm{O}_{2}$ and $97 \%(v / v) \mathrm{N}_{2}$ in the dark for $3 \mathrm{~h}$. The root samples were collected and frozen for analysis.

\subsection{RNA Extraction and Quantitative RT-PCR ( $q R T-P C R)$ Analyses}

The 14-day-old seedlings were hypoxia-treated for $3 \mathrm{~h}$. Then, root samples were collected in liquid nitrogen and stored at $-80^{\circ} \mathrm{C}$ until use. Total RNA was extracted using TRIzol (Invitrogen, Carlsbad, CA, USA) and then subjected to DNase treatment using the TURBO DNA-free kit (Ambion, Austin, TX, USA). RNA concentrations were determined, and samples were then reverse-transcribed into cDNAs by using Moloney murine leukemia virus reverse transcriptase (Invitrogen). qRT-PCR was conducted as previously described [52] and performed using a Rotor-Gene 3000 instrument (Corbett Research, Sydney, Australia) with Power SYBR Green PCR master mix (GeneMark, Taipei, Taiwan) in accordance with the manufacturers' recommendations. The Actin gene was used as an internal control 
for normalization. Relative expression levels were analyzed with Rotor-Gene 6 software (Corbett). Experiments were repeated five times independently with duplicate samples. The sequences of primers used for qRT-PCR are presented in Table 1.

Table 1. Primers used for quantitative RT-PCR experiments.

\begin{tabular}{cc}
\hline Gene Name & Primer Sequence \\
\hline$r A t E R F 73 / H R E 1$-forward & $5^{\prime}$-atcatgggcgatgcgaataa-3' \\
$r A t E R F 73 / H R E 1$-reverse & $5^{\prime}$-gcgagaaatattcggtctggtt-3' \\
$r A D H 1$-forward & $5^{\prime}$-catgaacaaggagctggagcttg-3' \\
$r A D H 1$-reverse & $5^{\prime}$-ctctccttcagcatgtaatcaaagg-3' \\
$r R b o h D$-forward & $5^{\prime}$-ccgagcagacggaggagat-3' \\
$r R b o h D$-reverse & $5^{\prime}$-tggaccgtcgataaggacctt-3' \\
\hline
\end{tabular}

\section{Conclusions}

In our previous studies, the data indicated that an increase in the transcript levels of $R b o h D$ was induced at a relatively early stage during hypoxic stress; for other hypoxia-inducible RBOHs, such as $R b o h A, B, F, G$, and $I$, transcript expressions were also affected by oxygen deprivation but not at a relatively early stage [24]. The involvement of other signaling elements in the complex signaling network associated with oxygen deprivation requires further evaluation.

Author Contributions: C.-P.H. conducted experiments and analyzed the data. M.-C.W. helps the statistical analysis and manuscript preparation. C.-Y.Y. conceived, designed research and wrote the manuscript. All authors have read and agreed to the published version of the manuscript.

Funding: This work was supported by the National Science Council, Taiwan (NSC101-2311-B-005-001) to Chin-Ying Yang.

Acknowledgments: We would like to thanks Ching-Hsiu Tsai for his kind help in the instrument assistance of quantitative RT-PCR.

Conflicts of Interest: The authors declare that they have no conflict of interest.

\section{References}

1. Wen, X.; Wang, J.; Zhang, D.; Wang, Y. A gene regulatory network controlled by bperf2 and bpmyb102 in birch under drought conditions. Int. J. Mol. Sci. 2019, 20, 3071. [CrossRef] [PubMed]

2. Savada, R.P.; Ozga, J.A.; Jayasinghege, C.P.A.; Kosala, D.; Waduthanthri, K.D.; Reinecke, D.M. Heat stress differentially modifies ethylene biosynthesis and signaling in pea floral and fruit tissues. Plant Mol. Biol. 2017, 95, 313-331. [CrossRef] [PubMed]

3. Huang, Y.C.; Yeh, T.H.; Yang, C.Y. Ethylene signaling involves in seeds germination upon submergence and antioxidant response elicited confers submergence tolerance to rice seedlings. Rice 2019, 12, 23. [CrossRef] [PubMed]

4. Abts, W.; Van de Poel, B.; Vandenbussche, B.; De Proft, M.P. Ethylene is differentially regulated during sugar beet germination and affects early root growth in a dose-dependent manner. Planta 2014, 240, 679-686. [CrossRef] [PubMed]

5. Choudhury, S.R.; Roy, S.; Das, R.; Sengupta, D.N. Differential transcriptional regulation of banana sucrose phosphate synthase gene in response to ethylene, auxin, wounding, low temperature and different photoperiods during fruit ripening and functional analysis of banana SPS gene promoter. Planta 2008, 229, 207-223. [CrossRef] [PubMed]

6. Eccher, G.; Begheldo, M.; Boschetti, A.; Ruperti, B.; Botton, A. Roles of ethylene production and ethylene receptor expression in regulating apple fruitlet abscission. Plant Physiol. 2015, 169, 125-137. [CrossRef] [PubMed]

7. Kepczynska, E.; Zielinska, S.; Kepczynski, J. Ethylene production by Agrobacterium rhizogenes strains in vitro and in vivo. Plant Growth Regul. 2003, 39, 13-17. [CrossRef]

8. Wang, H.H.; Liang, X.L.; Wan, Q.; Wang, X.M.; Bi, Y.R. Ethylene and nitric oxide are involved in maintaining ion homeostasis in Arabidopsis callus under salt stress. Planta 2009, 230, 293-307. [CrossRef] 
9. Yu, Y.W.; Yang, D.X.; Zhou, S.R.; Gu, J.T.; Wang, F.R.; Dong, J.G.; Huang, R.F. The ethylene response factor OsERF109 negatively affects ethylene biosynthesis and drought tolerance in rice. Protoplasma 2017, 254, 401-408. [CrossRef]

10. Li, W.Y.; Ma, M.D.; Feng, Y.; Li, H.J.; Wang, Y.C.; Ma, Y.T.; Li, M.Z.; An, F.Y.; Guo, H.W. EIN2-directed translational regulation of ethylene signaling in Arabidopsis. Cell 2015, 163, 670-683. [CrossRef]

11. Wang, K.L.C.; Li, H.; Ecker, J.R. Ethylene biosynthesis and signaling networks. Plant. Cell 2002, 14, S131-S151. [CrossRef]

12. Jackson, M.B. Ethylene-promoted elongation: An adaptation to submergence stress. Ann. Bot. 2008, 101, 229-248. [CrossRef]

13. Lenochova, Z.; Soukup, A.; Votrubova, O. Aerenchyma formation in maize roots. Biol. Plant. 2009, 53, 263-270. [CrossRef]

14. Yamauchi, T.; Yoshioka, M.; Fukazawa, A.; Mori, H.; Nishizawa, N.K.; Tsutsumi, N.; Yoshioka, H.; Nakazono, M. An NADPH oxidase RBOH functions in rice roots during lysigenous aerenchyma formation under oxygen-deficient conditions. Plant Cell 2017, 29, 775-790. [CrossRef] [PubMed]

15. Yamauchi, T.; Colmer, T.D.; Pedersen, O.; Nakazono, M. Regulation of root traits for internal aeration and tolerance to soil waterlogging-flooding stress. Plant Physiol. 2018, 175, 1118-1130. [CrossRef] [PubMed]

16. Steffens, B.; Geske, T.; Sauter, M. Aerenchyma formation in the rice stem and its promotion by $\mathrm{H}_{2} \mathrm{O}_{2}$. New Phytol. 2011, 190, 369-378. [CrossRef] [PubMed]

17. Choudhury, F.K.; Rivero, R.M.; Blumwald, E.; Mittler, R. Reactive oxygen species, abiotic stress and stress combination. Plant J. 2017, 90, 856-867. [CrossRef]

18. Baxter-Burrell, A.; Yang, Z.B.; Springer, P.S.; Bailey-Serres, J. RopGAP4-dependent Rop GTPase rheostat control of Arabidopsis oxygen deprivation tolerance. Science 2002, 296, 2026-2028. [CrossRef]

19. Yang, C.Y. Hydrogen peroxide controls transcriptional responses of ERF73/HRE1 and ADH1 via modulation of ethylene signaling during hypoxic stress. Planta 2014, 239, 877-885. [CrossRef]

20. Oda, T.; Hashimoto, H.; Kuwabara, N.; Akashi, S.; Hayashi, K.; Kojima, C.; Wong, H.L.; Kawasaki, T.; Shimamoto, K.; Sato, M.; et al. Structure of the N-terminal regulatory domain of a plant NADPH oxidase and its functional implications. J. Biol. Chem. 2010, 285, 1435-1445. [CrossRef]

21. Marino, D.; Dunand, C.; Puppo, A.; Pauly, N. A burst of plant NADPH oxidases. Trends Plant Sci. 2012, 17, 9-15. [CrossRef] [PubMed]

22. Monshausen, G.B.; Bibikova, T.N.; Weisenseel, M.H.; Gilroy, S. Ca ${ }^{2+}$ regulates reactive oxygen species production and $\mathrm{pH}$ during mechanosensing in Arabidopsis roots. Plant Cell 2009, 21, 2341-2356. [CrossRef] [PubMed]

23. Xie, Y.J.; Xu, S.; Han, B.; Wu, M.Z.; Yuan, X.X.; Han, Y.; Gu, Q.A.; Xu, D.K.; Yang, Q.; Shen, W.B. Evidence of Arabidopsis salt acclimation induced by up-regulation of HY1 and the regulatory role of RbohD-derived reactive oxygen species synthesis. Plant J. 2011, 66, 280-292. [CrossRef] [PubMed]

24. Zhang, Y.Y.; Zhu, H.Y.; Zhang, Q.; Li, M.Y.; Yan, M.; Wang, R.; Wang, L.L.; Welti, R.; Zhang, W.H.; Wang, X.M. Phospholipase D alpha 1 and phosphatidic acid regulate NADPH oxidase activity and production of reactive oxygen species in ABA-mediated stomatal closure in Arabidopsis. Plant. Cell 2009, 2, 2357-2377. [CrossRef] [PubMed]

25. Miller, G.; Schlauch, K.; Tam, R.; Cortes, D.; Torres, M.A.; Shulaev, V.; Dangl, J.L.; Mittler, R. The plant NADPH oxidase RbohD mediates rapid systemic signaling in response to diverse stimuli. Sci. Signal. 2009, 2, ra45. [CrossRef] [PubMed]

26. Yang, C.Y.; Hong, C.P. The NADPH oxidase Rboh D is involved in primary hypoxia signalling and modulates expression of hypoxia-inducible genes under hypoxic stress. Environ. Exp. Bot. 2015, 115, 63-72. [CrossRef]

27. Dunand, C.; Crevecoeur, M.; Penel, C. Distribution of superoxide and hydrogen peroxide in Arabidopsis root and their influence on root development: Possible interaction with peroxidases. New Phytol. 2007, 174, 332-341. [CrossRef]

28. Ruzicka, K.; Ljung, K.; Vanneste, S.; Podhorska, R.; Beeckman, T.; Friml, J.; Benkova, E. Ethylene regulates root growth through effects on auxin biosynthesis and transport-dependent auxin distribution. Plant Cell 2007, 19, 2197-2212. [CrossRef]

29. Loreti, E.; van Veen, H.; Perata, P. Plant responses to flooding stress. Curr. Opin. Plant Biol. 2016, 33 , 64-71. [CrossRef] 
30. White, M.D.; Kamps, J.; East, S.; Taylor Kearney, L.J.; Flashman, E. The plant cysteine oxidases from Arabidopsis thaliana are kinetically tailored to act as oxygen sensors. J. Biol. Chem. 2018, 293, 11786-11795. [CrossRef]

31. Hartman, S.; Liu, Z.; van Veen, H.; Vicente, J.; Reinen, E.; Martopawiro, S.; Zhang, H.; van Dongen, N.; Bosman, F.; Bassel, G.W.; et al. Ethylene-mediated nitric oxide depletion pre-adapts plants to hypoxia stress. Nat. Commun. 2019, 10, 4020. [CrossRef] [PubMed]

32. Perata, P. Ethylene signaling controls fast oxygen sensing in plants. Trends Plant Sci. 2020, 25, 3-6. [CrossRef] [PubMed]

33. Pogany, M.; von Rad, U.; Grun, S.; Dongo, A.; Pintye, A.; Simoneau, P.; Bahnweg, G.; Kiss, L.; Barna, B.; Durner, J. Dual roles of reactive oxygen species and NADPH oxidase RbohD in an Arabidopsis-Alternaria pathosystem. Plant Physiol. 2009, 151, 1459-1475. [CrossRef] [PubMed]

34. Liu, B.; Sun, L.; Ma, L.; Hao, F.S. Both AtrbohD and AtrbohF are essential for mediating responses to oxygen deficiency in Arabidopsis. Plant Cell Rep. 2017, 36, 947-957. [CrossRef]

35. Beaudoin, N.; Serizet, C.; Gosti, F.; Giraudat, J. Interactions between abscisic acid and ethylene signaling cascades. Plant Cell 2000, 12, 1103-1115. [CrossRef]

36. Liu, Y.G.; Ye, N.H.; Liu, R.; Chen, M.X.; Zhang, J.H. $\mathrm{H}_{2} \mathrm{O}_{2}$ mediates the regulation of ABA catabolism and GA biosynthesis in Arabidopsis seed dormancy and germination. J. Exp. Bot. 2010, 61, 2979-2990. [CrossRef]

37. Bai, L.; Zhou, Y.; Zhang, X.R.; Song, C.P.; Cao, M.Q. Hydrogen peroxide modulates abscisic acid signaling in root growth and development in Arabidopsis. Chin. Sci. Bull. 2007, 52, 1142-1145. [CrossRef]

38. Ivanchenko, M.G.; den Os, D.; Monshausen, G.B.; Dubrovsky, J.G.; Bednarova, A.; Krishnan, N. Auxin increases the hydrogen peroxide $\left(\mathrm{H}_{2} \mathrm{O}_{2}\right)$ concentration in tomato (Solanum lycopersicum) root tips while inhibiting root growth. Ann. Bot. 2013, 112, 1107-1116. [CrossRef]

39. Swarup, R.; Perry, P.; Hagenbeek, D.; Van Der Straeten, D.; Beemster, G.T.S.; Sandberg, G.; Bhalerao, R.; Ljung, K.; Bennett, M.J. Ethylene upregulates auxin biosynthesis in Arabidopsis seedlings to enhance inhibition of root cell elongation. Plant Cell 2007, 19, 2186-2196. [CrossRef]

40. Sauter, M. Root responses to flooding. Curr. Opin. Plant Biol. 2013, 16, 282-286. [CrossRef]

41. Munne-Bosch, S.; Alegre, L. Changes in carotenoids, tocopherols and diterpenes during drought and recovery, and the biological significance of chlorophyll loss in Rosmarinus officinalis plants. Planta 2000, 210, 925-931. [CrossRef] [PubMed]

42. Shi, Q.; Bao, Z.; Zhu, Z.; Ying, Q.; Qian, Q. Effects of different treatments of salicylic acid on heat tolerance, chlorophyll fluorescence, and antioxidant enzyme activity in seedlings of Cucumis sativa L. Plant. Growth Regul. 2006, 48, 127-135. [CrossRef]

43. Song, W.Y.; Park, J.; Mendoza-Cozatl, D.G.; Suter-Grotemeyer, M.; Shim, D.; Hortensteiner, S.; Geisler, M.; Weder, B.; Rea, P.A.; Rentsch, D.; et al. Arsenic tolerance in Arabidopsis is mediated by two ABCC-type phytochelatin transporters. Proc. Natl. Acad. Sci. USA 2010, 107, 21187-21192. [CrossRef] [PubMed]

44. Herrera, A. Responses to flooding of plant water relations and leaf gas exchange in tropical tolerant trees of a black-water wetland. Front. Plant Sci. 2013, 4, 150. [CrossRef] [PubMed]

45. Jacob-Wilk, D.; Holland, D.; Goldschmidt, E.E.; Riov, J.; Eyal, Y. Chlorophyll breakdown by chlorophyllase: Isolation and functional expression of the Chlase1 gene from ethylene-treated Citrus fruit and its regulation during development. Plant J. 1999, 20, 653-661. [CrossRef] [PubMed]

46. Qiu, K.; Li, Z.P.; Yang, Z.; Chen, J.Y.; Wu, S.X.; Zhu, X.Y.; Gao, S.; Gao, J.; Ren, G.D.; Kuai, B.K.; et al. EIN3 and ORE1 accelerate degreening during ethylene-mediated leaf senescence by directly activating chlorophyll catabolic genes in Arabidopsis. PLoS Genet. 2015, 11, e1005399. [CrossRef]

47. Gibbs, D.J.; Lee, S.C.; Isa, N.M.; Gramuglia, S.; Fukao, T.; Bassel, G.W.; Correia, C.S.; Corbineau, F.; Theodoulou, F.L.; Bailey-Serres, J.; et al. Homeostatic response to hypoxia is regulated by the N-end rule pathway in plants. Nature 2011, 479, 415-418. [CrossRef]

48. Hinz, M.; Wilson, I.W.; Yang, J.; Buerstenbinder, K.; Llewellyn, D.; Dennis, E.S.; Sauter, M.; Dolferus, R. Arabidopsis RAP2.2: An ethylene response transcription factor that is important for hypoxia survival. Plant Physiol. 2010, 153, 757-772. [CrossRef]

49. Ying, G.; Wang, Z.H.; Yang, Z.B. ROP/RAC GTPase: An old new master regulator for plant signaling. Curr. Opin. Plant Biol. 2004, 7, 527-536.

50. Matthews, S.; Khajeh-Hosseini, M. Length of the lag period of germination and metabolic repair explain vigour differences in seed lots of maize (Zea mays). Seed Sci. Technol. 2007, 35, 200-212. [CrossRef] 
51. Wintermans, J.F.G.M.; De Mots, A. Spectrophotometric characteristics of chlorophyll a and $b$ and their pheophytins in ethanol. Biochim. Biophys. Acta 1965, 109, 448-453. [CrossRef]

52. Lin, I.S.; Wu, Y.S.; Chen, C.T.; Chen, G.H.; Hwang, S.G.; Jauh, G.Y.; Tzen, J.T.C.; Yang, C.Y. AtRBOH I confers submergence tolerance and is involved in auxin-mediated signaling pathways under hypoxic stress. Plant Growth Regul. 2017, 83, 277-285. [CrossRef]

(C) 2020 by the authors. Licensee MDPI, Basel, Switzerland. This article is an open access article distributed under the terms and conditions of the Creative Commons Attribution (CC BY) license (http://creativecommons.org/licenses/by/4.0/). 